\title{
Lung Ultrasound Guided Fluid Management Protocol for the Critically III Patient: study protocol for a multi-centre randomized controlled trial
}

Daniel-Mihai Rusu ${ }^{1,2}$, lanis Siriopol ${ }^{1,2}$, loana Grigoras ${ }^{1,2^{*}}$, Mihaela Blaj ${ }^{1,3}$, Adi-lonut Ciumanghel $^{1,3}$, Dimitrie Siriopol ${ }^{1,4}$, Ionut Nistor ${ }^{1,4}$, Mihai Onofriescu ${ }^{1,4}$, Gigel Sandu ${ }^{3}$, Beatrice Cobzaru ${ }^{3}$, Dragos Viorel Scripcariu ${ }^{1,5}$,

Olguta Diaconu ${ }^{1,2}$ and Adrian Constantin Covic ${ }^{1,4}$

\begin{abstract}
Background: In routine intensive care unit (ICU) practice, fluids are often administered without a safety limit, which may lead to fluid overload and decreased survival. Recently, B-lines score (BLS) has been validated as a lung ultrasound (LUS) quantification of pulmonary congestion. This suggests that LUS may provide a safety threshold to conduct fluid therapy and to avoid overhydration. However, there is no randomized study to test the utility of LUS in guiding fluid management in ICU patients by using a pre-specified BLS cut-off value as a threshold for fluid removal.

Methods: LUS Guided Fluid Management Protocol for the Critically III Patient is a prospective, multi-centre, randomized controlled trial. Five hundred ICU patients will be randomly assigned in a 1:1 ratio, to protocolized LUS-based fluid management or usual care. The trial intervention will start on ICU admission and will consist in daily assessment of BLS and triggered evacuation of excessive fluids with loop diuretics (Furosemide) when BLS $\geq 15$. If rebalancing volume status with diuretics fails, forced evacuation by ultrafiltration will be used. The main endpoint is death from all causes at 28 days from randomization. The secondary outcomes are presence and time-course evolution of organ dysfunctions, ICU- and hospital length of stay, all-cause mortality at 90 days, and health economics data.
\end{abstract}

Discussion: If study results will show that LUS guided fluid management protocol improves outcome in ICU patients, it will be the base for other studies to refine this protocol or track those categories of critically ill patients to whom it may bring maximum benefits.

Trial registration: ClinicalTrials.gov, NCT03393065. Registered on 8 January 2018.

Keywords: Lung ultrasonography, B-lines score, Fluid management, Intensive care, Critically ill patient, Randomized controlled trial

\section{Background}

In critically ill patients, fluids are used to optimize organ perfusion, compensate fluid losses, avoid fluid deficiency, and deliver medication, antibiotics, or nutrition. However, when in excess, fluids may induce organ dysfunctions

\footnotetext{
* Correspondence: ioana.grigoras.ro@gmail.com; ioanagrigoras.ro@gmail.com ${ }^{1}$ Grigore T. Popa University of Medicine and Pharmacy, Str. Universității nr. 16, 700115 lasi, Romania

${ }^{2}$ Anaesthesia and Intensive Care Department, Regional Institute of Oncology, Str. General Henri Mathias Berthelot 2-4, 700483 lasi, Romania Full list of author information is available at the end of the article
}

[1-3], prolong intensive care unit (ICU) and hospital length of stay $[4,5]$, and even decrease survival [2-11]. Despite evidence regarding harmful effects of overhydration, in routine ICU practice, fluids are often administered without a safety limit [12] and diuretics are frequently prescribed without an agreement upon what would be the targeted endpoint [13]. These practices may be attributed to the drawbacks of currently used volume assessment methods.

In recent years, LUS has emerge as a novel tool to assess overhydration and has been successfully used in patients from the nephrology [14-19], cardiology [20], and ICU

(c) The Author(s). 2019 Open Access This article is distributed under the terms of the Creative Commons Attribution 4.0 International License (http://creativecommons.org/licenses/by/4.0/), which permits unrestricted use, distribution, and 
departments [21-24]. LUS has the advantages of being safe, non-invasive, rapidly available, and already part of different diagnostic algorithms for life-threatening conditions [25-27]. Being able to detect in real time the increase of extravascular lung water (EVLW) [28, 29], as well as the response to excessive fluids removal $[19,20]$, LUS may provide a valuable safety threshold to conduct fluid therapy and to optimize volume status.

The sonographic signs of increased EVLW are the artefacts called B-lines [24, 30-37]. B-lines are hyperechoic, comet-tail artefacts, which emerge from the level of the pleural line and move synchronously with lung sliding [38, 39]. The correlation between B-lines and the amount of EVLW has been demonstrated, by comparing LUS with gold standard methods for EVLW assessment [21, 24, 32]. B-lines presence may be evaluated by scanning the chest, from the second to the fourth intercostal space on the left side, and from the second to the fifth intercostal space on the right side, at parasternal, mid-clavicular, anterior-axillary, and mid-axillary lines, with the patient in supine position [35, 36]. The sum of all B-lines yields a score, B-lines score (BLS), which assess the degree of lung congestion $[24,39]$. A BLS $<5$ is considered normal, while a BLS $>15$ reflects moderate/severe pulmonary congestion [39].

Some prospective studies have shown that a high BLS is linked to a higher risk of mortality in dialysis patients $[17,40]$ and heart failure patients [41-45]. Few prospective studies have also used LUS as a prognostic tool in critically ill patients $[22,46]$. However, there is no randomized study to test the utility of LUS in guiding fluid management in ICU patients, by using a pre-specified BLS cut-off value, as a threshold for fluid removal.

\section{Study hypothesis}

Starting from the premises that mortality may be decreased by avoiding fluid overload and LUS may detect overhydration in early stages, we believe that daily evaluation of BLS, as a refined LUS quantification of pulmonary congestion and triggered evacuation of excessive fluids with diuretics or by ultrafiltration when BLS $\geq 15$, may improve outcome in critically ill patients.

Secondary hypotheses are that this intervention is cost-effective and may prevent or, if already present, may improve time-course evolution of organ dysfunctions, may reduce the ICU and hospital length of stay, and increase 90-day survival.

\section{Objectives}

The aim of this study is to evaluate a fluid management protocol for adult ICU patients, based on the daily assessment of BLS using LUS, compared to usual care. A pre-specified BLS cut-off value of 15 will be used in this randomized study to correct fluid overload. The selected cut-off value is recommended by Picano et al. as the limit between absent/mild to moderate/severe lung congestion [39].

\section{Methods/Design Study design}

LUS Guided Fluid Management Protocol for the Critically Ill Patient is a multi-centre, randomized controlled two-arm trial, with 1:1 allocation of ICU patients to LUS guided fluid management or usual care.

While hospitalized in the ICU, participants will be randomly assigned to receive LUS guided fluid management or usual care, until ICU discharge or for up to 28 days after randomization, whichever comes first.

The main endpoint will be all-cause mortality at 28 days from randomization (ICU admission).

The Standard Protocol Items: Recommendations for Interventional Trials (SPIRIT) checklist is provided in Additional file 1 and the schedule of study procedures (SPIRIT figure) is shown in Fig. 1.

\section{Settings}

The trial will be conducted in the ICUs of two university hospitals: Saint Spiridon University Hospital and Regional Institute of Oncology Iasi. The ICUs involved in the trial follow the recommendations of the Society of Critical Care Medicine regarding ICU admission and discharge criteria [47], can deliver the same high level of care, and have physicians capable to provide LUS guided fluid therapy. A rapid response team exists in each of these hospitals and ensures on-demand, hospital ward guidance for the management of patients with deteriorating conditions, as well as the evaluation of patients that may benefit from ICU admission.

\section{Participants}

We aim to enroll 500 adult ICU patients over a period of 24 months. To identify eligible individuals, a daily screening of all critically care admissions will be performed by study investigators. Patients will be included in this study if they are expected to stay at least $48 \mathrm{~h}$ in the ICU, meet at least one of the following inclusion criteria, and have none of the exclusion criteria.

\section{Inclusion criteria}

1. Major surgery

2. Major co-morbidities in surgical patients

3. Polytrauma with Injury Severity Score (ISS) $\geq 15$

4. Acute Physiology and Chronic Health Evaluation II Score (APACHE II) on admission $\geq 10$

5. Sequential Organ Failure Assessment Score (SOFA) on admission $\geq 6$ 


\begin{tabular}{|c|c|c|c|c|c|c|}
\hline \multicolumn{7}{|c|}{ STUDY PERIOD } \\
\hline & $\begin{array}{l}\text { Enrolment and } \\
\text { Allocation }\end{array}$ & \multicolumn{4}{|c|}{ Post-allocation } & \multirow{2}{*}{$\begin{array}{c}\text { Close-out } \\
2 \text { years } \\
\end{array}$} \\
\hline TIMEPOINT & ICU admission & $\begin{array}{l}\text { ICU } \\
\text { stay }\end{array}$ & $\begin{array}{l}\text { ICU discharge / 28-day } \\
\text { whichever comes first }\end{array}$ & $\begin{array}{c}28 \\
\text { days }\end{array}$ & 90 days & \\
\hline \multicolumn{7}{|l|}{ ENROLMENT: } \\
\hline Eligibility screen & $\mathrm{X}$ & & & & & \\
\hline Informed consent & $\mathrm{X}$ & & & & & \\
\hline Randomization & $\mathrm{X}$ & & & & & \\
\hline \multirow{2}{*}{\multicolumn{7}{|c|}{$\begin{array}{l}\text { INTERVENTIONS: } \\
\text { LUS guided fluid therapy }\end{array}$}} \\
\hline & & & $\vec{\longrightarrow}$ & & & \\
\hline Usual care & $\mapsto$ & & $\underset{\longrightarrow}{\longrightarrow}$ & & & \\
\hline \multicolumn{7}{|l|}{ ASSESSMENTS: } \\
\hline Baseline data & $\mathrm{X}$ & & & & & \\
\hline Severity scores & $\mathrm{x}$ & & & & & \\
\hline Physiological variables & $\mathrm{X}$ & $\mathrm{X}$ & $\mathrm{X}$ & & & \\
\hline Blood Tests & $\mathrm{X}$ & $\mathrm{X}$ & $\mathrm{X}$ & & & \\
\hline Serum biomarkers & $\mathrm{X}$ & $\mathrm{X}$ & $\mathrm{X}$ & & & \\
\hline Fluid Balance & $\mathrm{x}$ & $\mathrm{X}$ & $\mathrm{x}$ & & & \\
\hline BLS (active group) & $\mathrm{X}$ & $\mathrm{X}$ & $\mathrm{X}$ & & & \\
\hline Diuretic therapy & $\mathrm{X}$ & $\mathrm{X}$ & $\mathrm{X}$ & & & \\
\hline Organ dysfunctions & $\mathrm{X}$ & $\mathrm{X}$ & $\mathrm{X}$ & & & \\
\hline Hemodynamic support & $\mathrm{X}$ & $\mathrm{X}$ & $\mathrm{X}$ & & & \\
\hline Respiratory support & $\mathrm{X}$ & $\mathrm{X}$ & $\mathrm{X}$ & & & \\
\hline Renal replacement therapy & $\mathrm{X}$ & $\mathrm{x}$ & $\mathrm{X}$ & & & \\
\hline Patient's survival & & & & $\mathrm{X}$ & $\mathrm{X}$ & \\
\hline ICU length of stay & & & & $\mathrm{X}$ & $\mathrm{X}$ & \\
\hline Hospital length of stay & & & & & $\mathrm{X}$ & \\
\hline Resource utilization & & & & & & $\mathrm{X}$ \\
\hline
\end{tabular}

Fig. 1 The schedule of study procedures (SPIRIT figure)

\section{Exclusion criteria}

1. Patient's refusal

2. Age $<18$ years

3. Pregnancy

4. Patient with known pulmonary conditions that interfere with the interpretation of LUS: pneumectomy; pulmonary fibrosis; persistent pleural effusion

5. Stage 5 chronic kidney disease or indication for emergency renal replacement therapy (RRT)

6. Prolonged resuscitation ( $\geq 10 \mathrm{~min}$ ) for cardiorespiratory arrest

\section{Ethical aspects}

The study was approved by the Research Ethics Committee of the Grigore T. Popa University of Medicine and Pharmacy Iasi (date 14 November 2017, number 26261) and by the Research Ethics Committees of each hospital involved in the trial. Patients will receive written information about the nature of the trial, its aims and expected advantages, as well as possible risks, and they will be asked to sign an informed consent. If a patient is unable to give consent at the time of ICU admission, a legally authorized representative may give authorization. Once the participant regains capacity, the individual will be asked to confirm or withdraw consent.

\section{Randomization and blinding}

Study patients will be randomly assigned to either LUS guided fluid management or usual care, in a 1:1 ratio, using block randomization. The randomized block design will be created using a computer-based program by a study team member not involved in patient enrollment and treatment. This team member will securely guard the randomized block design at the coordinating center and will provide the allocation sequence each time a new patient is enrolled. Due to study design, patients and ICU physicians cannot be blinded, but the researcher that investigates primary and secondary outcomes will be blinded to patient group assignment.

\section{Study interventions}

LUS guided fluid management (active group)

LUS guided fluid management is based on BLS assessment using LUS, within the first $24 \mathrm{~h}$ of ICU admission, and daily thereafter, until ICU discharge, or for up to 28 days after randomization, whichever comes first.

After the initial LUS examination, the follow-up LUS will be performed daily, in the morning, at set times, between $9 \mathrm{am}$ and $11 \mathrm{am}$. The rationale for this approach is that all ICU patients will have daily, in the morning, a full clinical examination and a complete set of laboratory tests, providing evaluation of fluid status. In this way, all collected data may be further correlated with LUS findings.

LUS examinations will be performed at bedside, with the patient in a supine position, using the 28 zone technique and the GE LOGIQ V2 ${ }^{\circ}$ ultrasound system with the GE 3Sc-RS Cardiac Sector Probe ${ }^{\ominus}(1.5-4.0 \mathrm{MHz}$ frequency). The focus of the image will be set at the level of the pleural line and the depth of penetration at 
around $4-8 \mathrm{~cm}$. The image will be optimized by regulating the gain. The lungs will be scanned, from the second to the fourth intercostal space on the left side, and from the second to the fifth intercostal space on the right side, at parasternal, mid-clavicular, anterior-axillary, and mid-axillary lines. B-lines will be recorded in each intercostal space (28 sites of examination). The sum of all B-lines will produce a score, BLS, reflecting the extent of EVLW accumulation.

The ICU physician may recommend fluid therapy or vasoactive drugs with types and amounts at his/her choice. However, when signs of moderate/severe pulmonary congestion are seen on LUS exam (BLS $\geq 15$ ), a negative 24-h fluid balance $(250-1000 \mathrm{~mL})$ will be intended according to clinical judgement.

To achieve this goal, a protocolized intravenous administration of furosemide will be used, under careful monitoring of diuretic response. Diuretic administration will start with a furosemide dose $\leq 80 \mathrm{mg} /$ day which will be further adapted based on the next 24-h fluid balance, the follow-up BLS, and the previous diuretic regimen. If a negative fluid balance of $>1000 \mathrm{~mL} / 24 \mathrm{~h}$ is obtained and BLS is still $\geq 15$, the initial dose of diuretic will be reduced. If a negative fluid balance of $<1000 \mathrm{~mL} / 24 \mathrm{~h}$ is obtained and BLS is still $\geq 15$, the administered diuretic dose will be maintained. If negative fluid balance is not achieved and BLS is still $\geq 15$, the dose of diuretic will progressively be increased until the goal is attained. The maximum dose of furosemide will not exceed $800 \mathrm{mg} /$ day.

In case of a fall in blood pressure or an increase in creatinine blood level that is perceived to be due to a transient episode of intravascular fluid depletion, the diuretic may be temporarily stopped or the dose may be decreased according to clinical judgement. After the patient has stabilized and if BLS is $\geq 15$, diuretics will be reinitiated until the patient's BLS is $<15$. If the target of depleting overhydrated patients with diuretics cannot be achieved, RRT will be used. For RRT, the treating physician may choose between slow continuous ultrafiltration, continuous veno-venous hemofiltration, continuous veno-venous hemodialysis, or continuous veno-venous hemodiafiltration. Along with the goal of rebalancing fluid status, the choice of RRT technique should rely on patients' particularities and other goals of homeostasis restoration.

As acute kidney injury (AKI) is often present in ICU patients, and RRT is a common procedure during critical care, to avoid bias, AKI will be diagnosed in all patients based on changes in the serum creatinine, urine output, or both, according to the KDIGO recommendations [48].

In AKI patients, the following criteria for RRT initiation will be used:

1. Stage 3 AKI (urine output $<0.3 \mathrm{~mL} / \mathrm{kg} / \mathrm{h}$ for $\geq 24 \mathrm{~h}$ and/or $>3$-fold increase in serum creatinine level compared with baseline, or serum creatinine of $\geq 4$ $\mathrm{mg} / \mathrm{dL}$ with an acute increase of at least $0.5 \mathrm{mg} / \mathrm{dL}$ within $48 \mathrm{~h}$ )

2. Urine production $<200 \mathrm{~mL} / 12 \mathrm{~h}$ or anuria

3. Serum potassium level $>6 \mathrm{mEq} / \mathrm{L}$ and/or with electrocardiographic abnormalities

4. Organ edema in the presence of AKI resistant to diuretic treatment

5. A pH $<7.15$ in the context of either pure metabolic acidosis or mixed acidosis

6. Acute pulmonary edema due to fluid overload responsible for severe hypoxemia despite diuretic therapy

The algorithm of study protocol is shown in Fig. 2 and the recommended diuretic regimen in patients with BLS $\geq 15$ is shown in Table 1 .

\section{Usual care (control group)}

Usual care is defined as fluid and diuretics administration according to the clinical judgement of the treating ICU physician. The prescribed fluid's type and amount, as well as the dose of diuretics, will be at the discretion of the ICU physician, guided by clinical and laboratory data, except LUS.

\section{Data collection and follow-up}

Data will be collected on paper-based Case Report Forms and in a secure electronic database for further analysis.

\section{Clinical data}

Baseline data will include patients' age, gender, weight and height, reason of ICU admission, data on acute conditions and co-morbidities, on recent immunosuppressive treatments, inflammatory status, infectious status, and severity scores (APACHE II, SOFA, and ISS [only for polytrauma patients]). Except for SOFA severity score, which will be recorded daily, all other severity scores will be calculated once, at ICU admission.

Physiological variables (temperature, heart rate, blood pressure, cardiac rhythm, peripheral blood oxygen saturation, presence of pulmonary crackles or edema), as well as routine laboratory tests (complete blood count, serum electrolytes, urea, and creatinine), will be recorded daily, during ICU stay. Based on case complexity and evolution, all other needed monitoring parameters (e.g. invasive hemodynamic monitoring parameters) and laboratory tests (e.g. arterial-blood gas tests, central venous oxygen saturation, lactate level, inflammatory and infectious biomarkers) will be recorded.

\section{Biomarkers}

Blood samples will be collected and stored from all study patients, regardless of group allocation, for biomarkers 


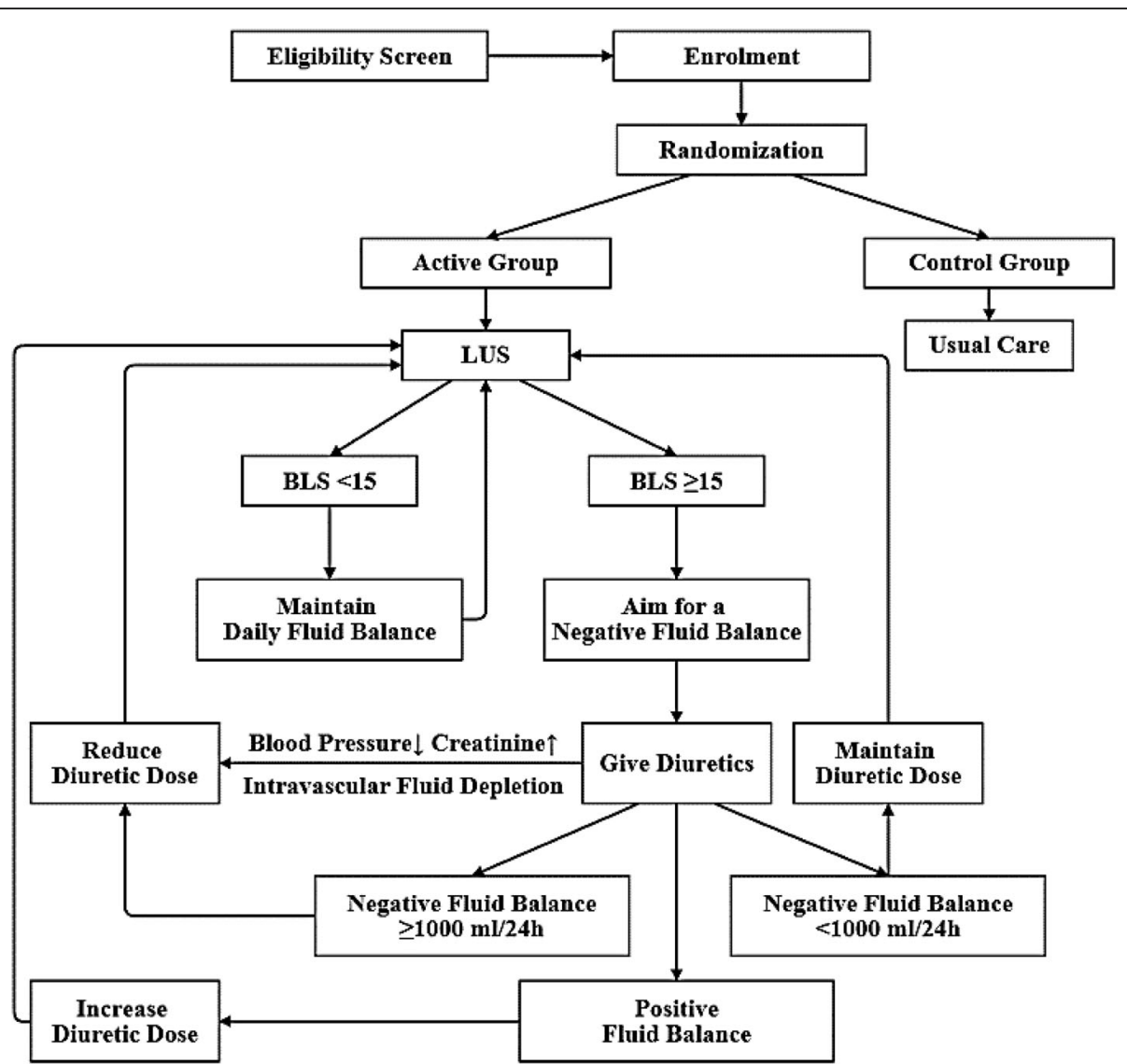

Fig. 2 Algorithm of study protocol

measurement. Serum brain natriuretic peptide (NTproBNP), interleukin-6 (IL-6), and neutrophil gelatinase-associated lipocalin (NGAL) will be assessed by electro-chemiluminescence "sandwich" immunoassays, using the Roche Elecsys ${ }^{\oplus}$ kit, based on polyclonal antibodies against NT-proBNP, IL-6, and NGAL, respectively. Blood samples will be collected on ICU admission, on the third, fifth, and seventh day of ICU stay, and weekly thereafter, until ICU discharge.

\section{Fluid balance and diuretics regimen}

Detailed data about daily fluid balance, including route, type and amount of fluid solutions received, and type

Table 1 Recommended intravenous diuretic regimen in patients with $\mathrm{BLS} \geq 15$

\begin{tabular}{lll}
\hline & Furosemide (mg/day) & \\
\cline { 2 - 3 } & Previous daily dose & Recommended daily dose \\
\hline 1 & $\leq 80$ & $40 \mathrm{mg}$ i.v. bolus $+5 \mathrm{mg} / \mathrm{h}$ \\
2 & $81-160$ & $80 \mathrm{mg}$ i.v. bolus $+10 \mathrm{mg} / \mathrm{h}$ \\
3 & $161-240$ & $80 \mathrm{mg}$ i.v. bolus $+20 \mathrm{mg} / \mathrm{h}$ \\
4 & $>240$ & $80 \mathrm{mg}$ i.v. bolus $+30 \mathrm{mg} / \mathrm{h}$ \\
\hline
\end{tabular}

and volume of fluid losses, as well as data upon diuretic therapy, will be collected daily, during ICU stay.

BLS will be recorded daily in the active group only.

\section{Outcome data}

Presence and time-course evolution of organ dysfunctions as well as specific therapeutic interventions will be recorded accordantly: hemodynamic support (drug type, dose, and duration of treatment); respiratory support (number of hours on mechanical ventilation); and RRT (type, duration, dose of dialysis, volume of removed fluid, pre and post dialysis BLS in active group only). All complications related to the RRT use will be recorded.

Survival/non-survival at 28 and 90 days since randomization.

\section{Primary outcome}

The main outcome will be death from all causes at 28 days from randomization. This will be assessed by a study team researcher, blinded to patient group assignment, based on hospital recordings or a brief telephone interview with the patient or patients' legally authorized representative or relative. 


\section{Secondary outcomes}

Secondary outcomes will include: presence and timecourse evolution of organ dysfunctions during ICU stay; changes in SOFA severity score and biomarkers (NT-proBNP, IL-6, NGAL); ICU length of stay; total hospital length of stay; all-cause mortality at 90 days; resource utilization; and cost-benefit ratio of used fluid solutions (crystalloids/colloids). Secondary outcomes will be assessed based on recorded data during ICU stay, hospital files, and a short telephone interview with the patient or patients' legally authorized representative to establish 90 days' survival.

\section{Strategies to ensure adequate enrolment and protocol compliance}

Case Report Forms will be uploaded into a secure database at the trial coordination center in a timely manner. This will allow periodical checks for enrolment rates, data accuracy, and protocol compliance. Whenever necessary, trial coordination center will provide support and feedback to the site investigators.

A safety interim analysis will be conducted after the enrolment of the first 100 patients.

\section{Statistical analysis}

Statistical analysis will be performed using SPSS (SPSS Inc., Chicago, IL, USA) and conducted on an intention-to-treat basis. Frequency distributions will be calculated for all variables and descriptive statistics will be used to define patient's characteristics in both arms. Study groups will be compared using non-parametric and parametric statistics, according to the types of variables analyzed.

The relative risk of 28-day mortality, with $95 \%$ confidence interval, will be assessed in both trial arms. Based on identified mortality-associated variables, we will also perform sensitivity analyses, subgroups analyses, and interactions tests.

Secondary outcomes will be analyzed using univariate analysis and competing-risk methods.

\section{Sample size power calculation}

Based on sample size power calculations, for a targeted power of $80 \%$ and alpha value of 0.05 , the number of patients needed to reveal a significant decrease of $10 \%$ in mortality is about 500 (250 in each arm). The mortality benefit estimation is based on a large cohort study of ICU patients, which showed that without any specific intervention, the presence/absence of fluid overload resulted in a mortality rate of $20 \%$ and $16.8 \%$, respectively [4].

\section{Strengths and limitations of the study protocol}

To our knowledge, this is the first prospective randomized controlled study that aims to evaluate a fluid management protocol for adult ICU patients, based on the daily assessment of BLS compared to usual care. A pre-specified BLS cut-off value of 15 will be used to assess fluid overload.

Our study will address both surgical and medical ICU patients. To identify eligible patients, we use severity scoring systems, but inclusion criteria are not limited to them, as scoring systems alone may be poor determinants of the level of care. ICU patients at risk for postsurgical organ dysfunction due to surgery magnitude or co-morbidities are also included.

LUS data may depend on examiner, ultrasound system, and patients' particularities. In order to minimize bias, LUS will be performed by previously trained investigators, using the same type of ultrasound equipment, probe, and technique. Patients with pulmonary conditions known to interfere with BLS evaluation (pneumectomy, pulmonary fibrosis, persistent pleural effusion) will be excluded, but other conditions, such as obesity, extrapulmonary diseases in the examination area, cardiac assist devices, or wound dressing, may also render the LUS examination difficult. To monitor LUS efficiency, B-lines will be counted in every site of examination and inaccessible sites for B-lines visualization will be noted. Although we cannot exclude all bias, the before mentioned strategies aim to minimize potential errors.

Diuretic prescription in overhydrated hemodynamically unstable patients may result in decreased protocol adherence. Therefore, protocol deviations (e.g. deviation from diuretic regimen) will be recorded and analyzed.

Due to the study design, the ICU physician in charge is not blinded to each patient's group allocation. Investigators in charge with biomarkers measurement and outcome assessment will be blinded. This may influence fluids and diuretics prescription, which may further modify the incidence of fluid overload and alter the results.

\section{Discussion}

The attempt to improve fluid management in critically ill patients has led in the last few years to a refined approach, centred on volemic status and fluid responsiveness assessment. Many studies have addressed the hemodynamically unstable patient and assessed different methods used to predict fluid responsiveness [49]. Less attention has been given to the diagnosis and management of fluid overload, mainly in patients at risk for organ dysfunction. Our study protocol includes patients at risk (patients after major surgery, surgical patients with major co-morbidities) and concentrates on active measures to detect and correct fluid overload.

Dynamic measurements of cardiac output and related parameters, although proven to be superior to static methods in directing fluid therapy [49], are still marginally used in clinical practice [50]. Offering fast results, being safe, non-invasive, and easy to learn $[39,51,52]$, 
LUS has the potential to overcome the drawbacks of other fluid assessments methods. If our study hypothesis proves to be right, LUS and BLS may help to discriminate between patients that may benefit from further fluid repletion and patients in which a fluid evacuation strategy should be adopted. LUS is not supposed to replace invasive hemodynamic monitoring or other methods used to assess fluid responsiveness, but to help intensive care physicians by providing a safety threshold for fluid resuscitation. More than this, for patients with pulmonary congestion, an algorithm for fluid management is proposed, with specific therapeutic measures that should be taken in order to achieve specific endpoints.

Study results will be submitted to an ISI indexed scientific journal. Other dissemination methods will include presentations at national and international scientific meetings. Favourable results may also be the ground for further research aiming for fluid management protocols based on non-invasive, simple, reliable, bedside techniques.

\section{Trial status}

Patient enrollment in the trial started in November 2017 and is expected to end in October 2019. The trial is registered at ClinicalTrials.gov, NCT03393065. Registered on 8 January 2018 - retrospectively registered. Protocol version: 1.

\section{Additional file}

Additional file 1: SPIRIT Checklist. (DOCX $50 \mathrm{~kb}$ )

\section{Abbreviations}

AKI: Acute kidney injury; APACHE II: Acute Physiology and Chronic Health Evaluation II Score; BLS: B-lines score; EVLW: Extravascular lung water; ICU: Intensive Care Unit; IL-6: Interleukin-6; ISS: Injury Severity Score; LUS: Lung ultrasound; NGAL: Neutrophil gelatinase-associated lipocalin; NT-proBNP: Brain natriuretic peptide; RRT: Renal replacement therapy; SOFA: Sequential Organ Failure Assessment Score

\section{Acknowledgements}

Not applicable.

\section{Funding}

The study has received a grant from The Romanian Ministry of Education, The Executive Unit for Funding for Higher Education, Research, Development and Innovation (UEFISCDI), project number PN-III-P4-ID-PCE-2016-0908, contract number 167/2017, within PNCDI III. The funding body has no active role in the design of the study, collection, analysis, and interpretation of data and in writing the manuscript.

\section{Availability of data and materials}

Not applicable.

\section{Authors' contributions}

DMR and IS contributed equally to study design and drafting the manuscript IG, MB, DS, IN, and MO made substantial contributions to study design and were involved in revising the manuscript. AIC, GS, BC, DVS, and OD contributed substantially to the study. ACC conceived the study design and was involved in preparing and revising the manuscript. All authors read and approved the final manuscript.

\section{Ethics approval and consent to participate}

The study was approved by the Research Ethics Committees of the Grigore T. Popa University of Medicine and Pharmacy (date 14 November 2017, number 26261) and by the Research Ethics Committees of the participating hospitals. All patients sign an informed consent.

\section{Consent for publication}

All authors consent for publication of the submitted version of this protocol article.

\section{Competing interests}

The authors declare that they have no competing interests.

\section{Publisher's Note}

Springer Nature remains neutral with regard to jurisdictional claims in published maps and institutional affiliations.

\section{Author details}

${ }^{1}$ Grigore T. Popa University of Medicine and Pharmacy, Str. Universității nr. 16, 700115 lasi, Romania. ${ }^{2}$ Anaesthesia and Intensive Care Department, Regional Institute of Oncology, Str. General Henri Mathias Berthelot 2-4, 700483 lasi, Romania. ${ }^{3}$ Anaesthesia and Intensive Care Department, Saint Spiridon University Hospital, Iasi, Romania. ${ }^{4}$ Nephrology Department, Dr. C.I Parhon University Hospital, lasi, Romania. ${ }^{5}$ Surgery Department, Regional Institute of Oncology, lasi, Romania.

Received: 25 August 2018 Accepted: 3 April 2019

Published online: 25 April 2019

\section{References}

1. Salahuddin N, Sammani M, Hamdan A, Joseph M, Al-Nemary Y, Alquaiz R, et al. Fluid overload is an independent risk factor for acute kidney injury in critically ill patients: results of a cohort study. BMC Nephrol. 2017;18:45. https://doi.org/10.1186/s12882-017-0460-6.

2. Brotfain E, Koyfman L, Toledano R, Borer A, Fucs L, Galante O, et al. Positive fluid balance as a major predictor of clinical outcome of patients with sepsis/septic shock after ICU discharge. Am J Emerg Med. 2016;34:2122-6. https://doi.org/10.1016/j.ajem.2016.07.058.

3. Wang $N$, Jiang $L$, Zhu B, Wen $Y, X i$ XM. Fluid balance and mortality in critically ill patients with acute kidney injury: A multicenter prospective epidemiological study. Crit Care. 2015;19:371. https://doi.org/10.1186/ s13054-015-1085-4.

4. Child DL, Cao Z, Seiberlich LE, Brown H, Greenberg J, Swanson A, et al. The costs of fluid overload in the adult intensive care unit: Is a small-volume infusion model a proactive solution? Clinicoecon Outcomes Res. 2014;7:1-8. https://doi.org/10.2147/CEOR.S72776.

5. RENAL Replacement Therapy Study Investigators, Bellomo R, Cass A, Cole L, Finfer S, Gallagher M, et al. An observational study fluid balance and patient outcomes in the randomized evaluation of normal vs. augmented level of replacement therapy trial*. Crit Care Med. 2012;40:1753-60. https://doi.org/ 10.1097/CCM.0b013e318246b9c6.

6. Neyra JA, Li X, Canepa-Escaro F, Adams-Huet B, Toto RD, Yee J, et al. Cumulative fluid balance and mortality in septic patients with or without acute kidney injury and chronic kidney disease. Crit Care Med. 2016:44: 1891-900. https://doi.org/10.1097/CCM.0000000000001835.

7. Acheampong A, Vincent J-L. A positive fluid balance is an independent prognostic factor in patients with sepsis. Crit Care. 2015;19:251. https://doi. org/10.1186/s13054-015-0970-1.

8. de Oliveira FSV, Freitas FGR, Ferreira EM, de Castro I, Bafi AT, de Azevedo $L C P$, et al. Positive fluid balance as a prognostic factor for mortality and acute kidney injury in severe sepsis and septic shock. J Crit Care. 2015;30: 97-101. https://doi.org/10.1016/J.JCRC.2014.09.002.

9. Teixeira C, Garzotto F, Piccinni P, Brienza N, lannuzzi M, Gramaticopolo S, et al. Fluid balance and urine volume are independent predictors of mortality in acute kidney injury. Crit Care. 2013;17:R14. https://doi.org/10.1186/ cc12484.

10. Boyd JH, Forbes J, Nakada T, Walley KR, Russell JA. Fluid resuscitation in septic shock: A positive fluid balance and elevated central venous pressure are associated with increased mortality*. Crit Care Med. 2011;39:259-65. https://doi.org/10.1097/CCM.0b013e3181feeb15. 
11. Vincent JL, Sakr Y, Sprung CL, Ranieri VM, Reinhart K, Gerlach H, et al. Sepsis in European intensive care units: Results of the SOAP study. Crit Care Med. 2006;34:344-53. https://doi.org/10.1097/01.CCM.0000194725.48928.3A.

12. Cecconi M, Hofer C, Teboul JL, Pettila V, Wilkman E, Molnar Z, et al. Fluid challenges in intensive care: the FENICE study: A global inception cohort study. Intensive Care Med. 2015;41:1529-37. https://doi.org/10.1007/s00134015-3850-x.

13. Jones SL, Mårtensson J, Glassford NJ, Eastwood GM, Bellomo R. Loop diuretic therapy in the critically ill: A survey. Crit Care Resusc. 2015;17:223-6.

14. Covic A, Siriopol D, Voroneanu L. Use of lung ultrasound for the assessment of volume status in CKD. Am J Kidney Dis. 2018;71:412-22. https://doi.org/ 10.1053/j.ajkd.2017.10.009.

15. Donadio C, Bozzoli L, Colombini E, Pisanu G, Ricchiuti G, Picano E, et al. Effective and timely evaluation of pulmonary congestion: Qualitative comparison between lung ultrasound and thoracic bioelectrical impedance in maintenance hemodialysis patients. Medicine (Baltimore). 2015;94:e473. https://doi.org/10.1097/MD.0000000000000473.

16. Basso F, Milan Manani S, Cruz DN, Teixeira C, Brendolan A, Nalesso F, et al. Comparison and reproducibility of techniques for fluid status assessment in chronic hemodialysis patients. Cardiorenal Med. 2013;3:104-12. https://doi. org/10.1159/000351008.

17. Zoccali C, Torino C, Tripepi R, Tripepi G, D’Arrigo G, Postorino M, et al. Pulmonary congestion predicts cardiac events and mortality in ESRD. J Am Soc Nephrol. 2013;24:639-46. https://doi.org/10.1681/ASN.2012100990.

18. Panuccio V, Enia G, Tripepi R, Torino C, Garozzo M, Battaglia GG, et al. Chest ultrasound and hidden lung congestion in peritoneal dialysis patients. Nephrol Dial Transplant. 2012;27:3601-5. https://doi.org/10.1093/ndt/gfs 116.

19. Noble VE, Murray AF, Capp R, Sylvia-Reardon MH, Steele DJR, Liteplo A. Ultrasound assessment for extravascular lung water in patients undergoing hemodialysis: Time course for resolution. Chest. 2009;135:1433-9. https://doi. org/10.1378/chest.08-1811.

20. Platz E, Merz AA, Jhund PS, Vazir A, Campbell R, McMurray JJ. Dynamic changes and prognostic value of pulmonary congestion by lung ultrasound in acute and chronic heart failure: a systematic review. Eur J Heart Fail. 2017; 19:1154-63. https://doi.org/10.1002/ejhf.839.

21. Anile A, Russo J, Castiglione G, Volpicelli G. A simplified lung ultrasound approach to detect increased extravascular lung water in critically ill patients. Crit Ultrasound J. 2017;9:13. https://doi.org/10.1186/s13089-0170068-x.

22. Zhao Z, Jiang $L, X i X$, Jiang $Q$, Zhu B, Wang $M$, et al. Prognostic value of extravascular lung water assessed with lung ultrasound score by chest sonography in patients with acute respiratory distress syndrome. BMC Pulm Med. 2015;15:98. https://doi.org/10.1186/s12890-015-0091-2.

23. Enghard $P$, Rademacher $S$, Nee J, Hasper D, Engert U, Jörres A, et al. Simplified lung ultrasound protocol shows excellent prediction of extravascular lung water in ventilated intensive care patients. Crit Care. 2015;19:36. https://doi.org/10.1186/s13054-015-0756-5.

24. Agricola E, Bove T, Oppizzi M, Marino G, Zangrillo A, Margonato A, et al. "Ultrasound comet-tail images": a marker of pulmonary edema. Chest. 2005; 127:1690-5. https://doi.org/10.1378/chest.127.5.1690.

25. Lichtenstein DA, Mezière GA. Relevance of lung ultrasound in the diagnosis of acute respiratory failure: the BLUE protocol. Chest. 2008;134:117-25. https://doi.org/10.1378/chest.07-2800.

26. Lichtenstein D. Fluid administration limited by lung sonography: The place of lung ultrasound in assessment of acute circulatory failure (the FALLS-protocol). Expert Rev Respir Med. 2012;6:155-62. https:/doi.org/10.1586/ers.12.13.

27. Lichtenstein DA. How can the use of lung ultrasound in cardiac arrest make ultrasound a holistic discipline. The example of the SESAME-protocol. Med Ultrason. 2014;16:252-5. https://doi.org/10.11152/mu.2013.2066.163.dal1.

28. Pingitore A, Garbella E, Piaggi P, Menicucci D, Frassi F, Lionetti V, et al. Early subclinical increase in pulmonary water content in athletes performing sustained heavy exercise at sea level: ultrasound lung comet-tail evidence. Am J Physiol Heart Circ Physiol. 2011;301:H2161-7. https://doi.org/10.1152/ ajpheart.00388.2011.

29. Gargani L, Lionetti V, Di Cristofano C, Bevilacqua G, Recchia FA, Picano E. Early detection of acute lung injury uncoupled to hypoxemia in pigs using ultrasound lung comets. Crit Care Med. 2007:35:2769-74. https://doi.org/10. 1097/01.CCM.0000287525.03140.3F.

30. Dietrich CF, Mathis G, Blaivas M, Volpicelli G, Seibel A, Wastl D, et al. Lung Bline artefacts and their use. J Thorac Dis. 2016;8:1356-65. https://doi.org/10. 21037/jtd.2016.04.55.
31. Shyamsundar M, Attwood B, Keating L, Walden AP. Clinical review: The role of ultrasound in estimating extra-vascular lung water. Crit Care. 2013;17:237. https://doi.org/10.1186/cc12710.

32. Jambrik Z, Gargani L, Adamicza Á, Kaszaki J, Varga A, Forster T, et al. B-lines quantify the lung water content: A lung ultrasound versus lung gravimetry study in acute lung injury. Ultrasound Med Biol. 2010;36:2004-10. https://doi.org/10. 1016/j.ultrasmedbio.2010.09.003.

33. Soldati G, Copetti R, Sher S. Sonographic interstitial syndrome: the sound of lung water. J Ultrasound Med. 2009;28:163-74. https://doi.org/10.7863/jum. 2009.28.2.163.

34. Volpicelli G, Caramello V, Cardinale L, Mussa A, Bar F, Frascisco MF. Bedside ultrasound of the lung for the monitoring of acute decompensated heart failure. Am J Emerg Med. 2008;26:585-91. https://doi.org/10.1016/j.ajem. 2007.09.014.

35. Picano E, Frassi F, Agricola E, Gligorova S, Gargani L, Mottola G. Ultrasound lung comets: A clinically useful sign of extravascular lung water. J Am Soc Echocardiogr. 2006;19:356-63. https://doi.org/10.1016/j.echo.2005.05.019.

36. Jambrik Z, Monti S, Coppola V, Agricola E, Mottola G, Miniati M, et al. Usefulness of ultrasound lung comets as a nonradiologic sign of extravascular lung water. Am J Cardiol. 2004;93:1265-70. https://doi.org/10. 1016/j.amjcard.2004.02.012

37. Lichtenstein D, Meziere G, Biderman P, Gepner A, Barre O. The comet-tail artifact. An ultrasound sign of alveolar-interstitial syndrome. Am J Respir Crit Care Med. 1997;156:1640-6. https://doi.org/10.1164/ajrccm.156.5.96-07096.

38. Volpicelli G, Elbarbary M, Blaivas M, Lichtenstein DA, Mathis G, Kirkpatrick AW, et al. International evidence-based recommendations for point-of-care lung ultrasound. Intensive Care Med. 2012;38:577-91. https://doi.org/10. 1007/s00134-012-2513-4.

39. Picano E, Pellikka PA. Ultrasound of extravascular lung water: A new standard for pulmonary congestion. Eur Heart J. 2016;37:2097-104. https:// doi.org/10.1093/eurheartj/ehw164.

40. Siriopol D, Hogas S, Voroneanu L, Onofriescu M, Apetrii M, Oleniuc M, et al. Predicting mortality in haemodialysis patients: A comparison between lung ultrasonography, bioimpedance data and echocardiography parameters. Nephrol Dial Transplant. 2013;28:2851-9. https://doi.org/10.1093/ndt/gft260.

41. Platz E, Lewis EF, Uno H, Peck J, Pivetta E, Merz AA, et al. Detection and prognostic value of pulmonary congestion by lung ultrasound in ambulatory heart failure patients. Eur Heart J. 2016;37:1244-51. https://doi. org/10.1093/eurheartj/ehv745.

42. Cogliati C, Casazza G, Ceriani E, Torzillo D, Furlotti S, Bossi l, et al. Lung ultrasound and short-term prognosis in heart failure patients. Int J Cardiol. 2016;218:104-8. https://doi.org/10.1016/j.ijcard.2016.05.010.

43. Coiro S, Porot G, Rossignol P, Ambrosio G, Carluccio E, Tritto I, et al. Prognostic value of pulmonary congestion assessed by lung ultrasound imaging during heart failure hospitalisation: A two-centre cohort study. Sci Rep. 2016;6:39426. https://doi.org/10.1038/srep39426.

44. Coiro S, Rossignol P, Ambrosio G, Carluccio E, Alunni G, Murrone A, et al. Prognostic value of residual pulmonary congestion at discharge assessed by lung ultrasound imaging in heart failure. Eur J Heart Fail. 2015;17:1172-81. https://doi.org/10.1002/ejhf.344.

45. Gargani L, Pang PS, Frassi F, Miglioranza MH, Dini FL, Landi P, et al. Persistent pulmonary congestion before discharge predicts rehospitalization in heart failure: A lung ultrasound study. Cardiovasc Ultrasound. 2015;13:40. https://doi.org/10.1186/s12947-015-0033-4.

46. Ciumanghel A, Siriopol I, Blaj M, Siriopol D, Gavrilovici C, Covic A. B-lines score on lung ultrasound as a direct measure of respiratory dysfunction in ICU patients with acute kidney injury. Int Urol Nephrol. 2018;50:113-9. https://doi.org/10.1007/s11255-017-1730-8.

47. Nates JL, Nunnally M, Kleinpell R, Blosser S, Goldner J, Birriel B, et al. ICU admission, discharge, and triage guidelines: A framework to enhance clinical operations, development of institutional policies, and further research. Crit Care Med. 2016;44:1553-602. https://doi.org/10.1097/CCM.0000000000001856.

48. Fliser D, Laville M, Covic A, Fouque D, Vanholder R, Juillard L, et al. A European Renal Best Practice (ERBP) position statement on the Kidney Disease Improving Global Outcomes (KDIGO) Clinical Practice Guidelines on Acute Kidney Injury: Part 1: Definitions, conservative management and contrast-induced nephropathy. Nephrol Dial Transplant. 2012;27:4263-72. https://doi.org/10.1093/ndt/gfs375.

49. Bentzer P, Griesdale DE, Boyd J, MacLean K, Sirounis D, Ayas NT. Will this hemodynamically unstable patient respond to a bolus of intravenous fluids? JAMA. 2016;316:1298-309. https://doi.org/10.1001/jama.2016.12310. 
50. Miller TE, Bunke M, Nisbet P, Brudney CS. Fluid resuscitation practice patterns in intensive care units of the USA: A crosssectional survey of critical care physicians. Perioper Med. 2016;5:15. https://doi.org/10.1186/s13741016-0035-2.

51. Gullett J, Donnelly JP, Sinert R, Hosek B, Fuller D, Hill H, et al. Interobserver agreement in the evaluation of B-lines using bedside ultrasound. J Crit Care. 2015;30:1395-9. https://doi.org/10.1016/j.jcrc.2015.08.021.

52. Chiem AT, Chan CH, Ander DS, Kobylivker AN, Manson WC. Comparison of expert and novice sonographers' performance in focused lung ultrasonography in dyspnea (FLUID) to diagnose patients with acute heart failure syndrome. Acad Emerg Med. 2015;22:564-73. https://doi.org/10.1111/ acem.12651.

Ready to submit your research? Choose BMC and benefit from:

- fast, convenient online submission

- thorough peer review by experienced researchers in your field

- rapid publication on acceptance

- support for research data, including large and complex data types

- gold Open Access which fosters wider collaboration and increased citations

- maximum visibility for your research: over $100 \mathrm{M}$ website views per year

At BMC, research is always in progress.

Learn more biomedcentral.com/submissions 